Instructions for authors, subscriptions and further details:

\title{
http://mcs.hipatiapress.com
}

\section{Masculinities under Neoliberalism}

Pilar Alvárez-Cifuentes ${ }^{1}$

1) Universidad de Loyola-Andalucía, Spain

Date of publication: June $21^{\text {th }}, 2016$

Edition period: June 2016-October 2016

To cite this article: Álvarez, P. (2016). Masculinities under Neoliberalism [Review of the book]. Masculinities and Social Change, 5(2), 205-206-. doi: 10.17583/MCS.2016.2129

To link this article: http://dx.doi.org/10.4471/MCS.2016.2129

\section{PLEASE SCROLL DOWN FOR ARTICLE}

The terms and conditions of use are related to the Open Journal System and to Creative Commons Attribution License (CC-BY). 


\section{Reviews (I)}

Cornwall, A., Karioris, F. G., \& Lindisfarne, N. (Eds.) (2016). Masculinities under Neoliberalism. London: Zed Books. ISBN: 978-1783607662

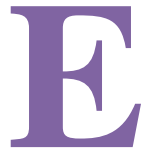

ste libro editado por Andrea Cornwall, Frank G. Karioris y Nancy Lindisfarne y publicado por Zed Books en el año 2016, plantea una serie de debates alrededor de los modelos de masculinidad y su vinculación con la economía neoliberal. Estos debates se concretan a través de diferentes capítulos, un total de 15, en los que un número de teóricos reconocidos analizan la definición de las identidades masculinas en distintas partes del mundo, tales como China, Zimbawe, Marruecos, Jamaica, Rusia, Brasil, Gran Bretaña, etc. El libro recoge la herencia antropológica del libro elaborado por Cornwall y Lindisfarne (1994) Dislocating Masculinity y también el riguroso estudio de Paul Willis en Aprendiendo a trabajar (1988).

En la introducción Cornwall realiza un análisis histórico de los men's studies, a través del cual presenta el papel central que tiene el neoliberalismo para la definición de las imágenes de género y los discursos ligados a la masculinidad. En este sentido, la autora apunta que el proceso de globalización está marcando de forma local la reconfiguración del género en las sociedades actuales. A continuación, en el siguiente capítulo, el libro traza en profundidad cuál es el vínculo entre la implementación de la economía neo-liberal y las masculinidades. En este marco se presenta el planteamiento teórico de la masculinidad hegemónica y de las feminidades subordinadas definiéndose como ejes centrales en el estudio de las identidades de género. De forma paralela también se subraya como la consolidación de estos dos modelos ha ido naturalizando la desigualdad, y 
como posteriormente, ello ha significado el asentamiento de narrativas de violencia.

En los capítulos posteriores los diferentes autores y autoras presentan investigaciones exhaustivas sobre la configuración de las masculinidades en diferentes partes del mundo. Por ejemplo, se realiza un amplio estudio sobre los hombres de clase obrera en Rusia destacando su pérdida de prestigio y respeto social, de hecho, se habla de una transición de ser hombres que eran venerados a ser denigrados. La evolución política, y el conocido como período post-soviético, han llevado a que la masculinidad dominante sea la que posea una mayor valoración en el país. Resulta interesante también otro capítulo en el que se estudia el papel de la paternidad en Angola. En él se concluye la importancia de la figura del padre que provee de formación y oportunidades laborales a sus hijos varones, ya que ello tiene un impacto directo en la prevención de la delincuencia.

En el capítulo 13 Mac an Ghaill y Haywood introducen elementos interesantes al estudio de las masculinidades en el contexto de economía neoliberal, en este caso en Gran Bretaña. Estos elementos son la multiculturalidad y la religión, que tienen una clara influencia en la consolidación de la cohesión social. En esta línea, en otros capítulos se introducen otras procedencias que seguro que despiertan gran curiosidad en el lector, como son Jamaica y Brasil. En relación a los primeros, la investigación llevada a cabo sobre los hombres en Jamaica pone énfasis en el papel socializador del futbol, mientras que en el estudio sobre los hombres brasileños se destaca su diversidad y su vinculación con la atracción erótica.

Pilar Álvarez-Cifuentes, Universidad Loyola-Andalucía palvarez@uloyola.es 